\title{
Hydro-mechanical Properties of Highly porous Limestone Rock used for Historic Monuments in North-East Tunisia
}

\author{
Yousr Koubaa $^{1 *}$, Mehrez Jamei ${ }^{1,2}$ and Houda Guiras ${ }^{1}$ \\ ${ }^{1}$ Laboratory of Civil Engineering, National Engineering School of Tunis, University of Tunis, El-Manar, Le Belvédère, Tunis, Tunisia \\ ${ }^{2}$ College of Engineering College, Northern Borders University, KSA
}

\begin{abstract}
This paper deals with the study of the physical and hydro-mechanical characteristics of a porous limestone rock. It concerns a historic rock located at "El-Haouaria artificial caves" on the seacoast in the Northeast of Tunisia. The rock, object of study in this work, has undergone serious alterations, thus compromising the safety of the monuments. This paper focuses on the mechanical behavior of a sedimentary rock with a variable porosity; covering a wide range varying from $25 \%$ to $55 \%$. This study is interested in identifying the mineralogical composition and the microscopic structure of the main rocks constituting the historic monument. Several tests were carried out and they showed that the rock's mineralogical composition was calcite and quartz. The grain dimensions constituting the rock are variable. Its porosity is inter-granular and connected. This porosity changes over time due to weather conditions. Unconfined compressive tests and tensile tests were carried out on several samples with various porosities and in some cases in various saturation states. The performed tests showed the effect of both porosity and water content (suction) on strength characteristics. However, despite the rock's dependency on the water content, the role of porosity remains more emphasized. Then, porosity seems to be the main factor affecting resistance properties due to the increase of the porosity and due to its variation as a source of humidity. A "Li and Aubertin's Model" was applied to predict the compression and tensile strength dependency on porosity. It highlighted a strong concordance between experimental and analytical model results. All strength characteristics evolutions with porosity and suction make up essential results obtained in this study. This will provide us with the required input data for modeling in order to predict cave structure degradation and eventually to monitor crack propagation.
\end{abstract}

Keywords: Monument; Limestone rock; Degradation; Porosity; Humidity; Suction; Weather conditions

\section{Introduction}

Many geotechnical and geological studies require a deeper understanding of the behavior of porous rocks. Some of these studies also deal with the durability of the rocks involved in monument restoration. [1-5]. By reviewing the literature, we noticed that several studies have described the mechanical compaction in various porous rocks including silicate rocks [6], and carbonate rocks [7,8].

On the other hand, it has been demonstrated that rock durability either depends on its intrinsic properties such as total porosity, pore connectivity, pore size distribution and particle size [9-13], or it is related to rock type mineralogy [14-19]. Some models were also recently proposed to predict the breakage of the rocks with high porosity including plastic shearing and pore collapse [20] and the damage occurring under chemical erosion [21].

Moreover, the stability of rock properties over time depends on the variety of geological and sedimentary processes such as deformation, and burial digenesis by several physicochemical mechanisms (e.g. rearrangement of grains, crystal plasticity, pressure solution and cementation). The role of porosity in the durability of porous stones has been investigated by taking into account the alteration of salt susceptibility [1,6] and pore structure [22-26]. The relationship between the changes in the microstructure and the porosity evolution was also established for some types of rocks, like the clay rock [27]. These authors have demonstrated that the changes of the microstructure due to the suction (in wetting and drying paths), affects strongly the macroscopic porosity, and then the mechanical characteristics. The decrease of suction (increase of water content) gives large decrease in tensile strength, and then creates the propagation and enlargement of cracks [27].

From another aspect, it is shown that the potential of porous rocks to absorb water depends on weather conditions (temperature and relative humidity). For instance, water is carried in the stone through the existing cracks affects the behavior of the material and therefore, it may be responsible for rock deterioration. In addition, water can act directly by means of gel dissolution of minerals, or indirectly by the carriage of soluble salts, and consequently, it enhances biological activity. Even though natural rocks can never be entirely saturated, many experimental works dealing with stone deterioration were performed under fully saturated rocks. Therefore, in order to understand stone damage mechanisms, it is necessary to implement experiments on stones having different water contents [28-29].

To study rock behavior and the stress-strain relationship, some authors have performed tests on the cylindrical samples subjected to compression efforts. Largely relying on these test types, many authors have contributed significantly to a general understanding of different rock types' strength and elastic deformation [30,31]. However, the understanding of rock behavior after strain-induced damage remains relatively poorly described [32,33]. A few authors have already published results focusing specifically on test results after damage and failure strength [34-40].

Although the exploitation of El-Haouaria caves ceased long ago, (since the Punic period in the 7th and 6th centuries AD), an apparent degradation has relatively surged in recent years, in the sense that the cracks reappeared and reopened in the last decades. Beside the longlasting impact of the environmental actions (cycles of humidity and

*Corresponding author: Yousr Koubaa, Laboratory of Civil Engineering, National Engineering School of Tunis, University of Tunis, El-Manar, B.P. 32, 1002, Le Belvédère, Tunis, Tunisia, Tel: +216 71887 713; E-mail: y.koubaa@gmail.com

Received November 26, 2017; Accepted May 08, 2018; Published May 14, 2018

Citation: Koubaa Y, Jamei M, Guiras H (2018) Hydro-mechanical Properties of Highly porous Limestone Rock used for Historic Monuments in North-East Tunisia. J Civil Environ Eng 8: 310. doi: 10.4172/2165-784X.1000310

Copyright: @ 2018 Koubaa Y, et al. This is an open-access article distributed under the terms of the Creative Commons Attribution License, which permits unrestricted use, distribution, and reproduction in any medium, provided the original author and source are credited. 
temperature gradients), the source of this degradation may be also attributed to some external actions (i.e., Earthquakes and non-controlled human activities in the vicinity of caves such as digging, excavation, etc.). The necessity to understand rock behavior in its current state and determine mechanical characteristics dependency on the typically environmental parameters was really suitable in order to develop a future convenient technical solution likely to assess cave stability.

In this paper, the study aims at investigating the behavior of the rocks in the caves when they are submitted to suction variation in order to use the results of issues for the exploration of the origin of surging cracks and the growth in the monument of El-Haouaria caves, particularly in rock $U 3$ as shown hereunder. Hence our work is summarized in the identification of rock microscopic characteristics and the analysis of hydro-mechanical tests at different stages of porosity and humidity (compression and tensile tests), and this in order to scrutinize:

- The microstructure of complex sedimentary rocks of "El-Haouaria caves", to determine the mineralogy, the intrinsic properties such as total porosity, pore connectivity, pore size distribution and particle size distribution,

- The water retention curve (WRC), which relates the water content to suction.

- The mechanical behavior of the cave rocks which display a wide range of porosity.

- The effect of microstructure and suction on the rock's mechanical behavior.

Unconfined compression and indirect tensile tests (three - point bending tests and splitting tests) have been performed on rock samples for several water contents. The experimental results - particularly those of unconfined compression and bending tests- show that porosity has a direct impact on rock mechanical properties, in addition to other characteristics such as the pore's size distribution, the degree of cementation and the size and shape of aggregates.

The discussion in this paper is focused on the effect of water content in terms of the increase of porosity by the wetting-drying cycles and the long dissolution phenomenon, which itself involves a decrease of the strength properties. Indeed, microscopic tests show that the shape and size of the constituent rock grass is variable from one sample to another, which causes variable porosity, cementation presence and its dissolution, thus creating some void between plants. In this sense, several wetting and drying cycles were carried out on the samples in order to understand their effect on rock porosity. From the several performed tests, rock degradation can be attributed in part to the change in rock porosity after several wetting and drying cycles. Moreover, the results show a high sensitivity of rock properties to saturation, particularly when the degree of the rock's water saturation exceeds $85 \%$. Tensile strength and unconfined compressive strength are almost halved compared to the driest states. The link between mechanical and retention properties is used to explain water content-mechanical resistance dependency.

\section{Literature Review}

\section{Geological formation and crack monitoring of 'El-Haouaria caves'}

'El-Haouaria caves' are located in the vicinity of El-Haouaria village in the "Cap Bon Finger" in Northern Tunisia. The caves were limestone quarries created in Punic era, in the $7^{\text {th }}$ and $6^{\text {th }}$ centuries B.C., and they had also been exploited in the Roman era. The rocks outside these caves were used in the construction of towns in those early days. Several monuments located in the coastal city of Tunisia such as the city of Carthage were built from these rocks. 'El-Haouaria caves' were immense caverns, half-hollowed, obscure and pyramidal. They were accessed by a narrow upper opening. For decades, the visit of the site is possible through larger side openings (Figure 1).

Actually, the visual examination of the composition on site reflects the lamination of five rock units (Figure 2). Five geological units are detected (U1 to U5). Our interest is focused on the study of hydromechanical properties of the rock $U 3$, since it is the thickest layer and it contains a series of developed cracks, which compromise the cave's stability (Figure 2). In order to measure the crack's opening variation in terms of temperature variation, we have monitored the cracks' opening. (Figures 3a-3c) give the localization of some cracks and the strain gauges which were placed in order to continuously record the deformation so as to obtain cracks' opening in the meantime.

As a monitoring process, some strain gages are installed in the layer rock $U 3$, where the cracks appeared. Gage information was automatically recorded in a connected computer. Measurements of some cracks openings lasting two years, in terms of temperature, were performed. Figure 3 shows an example of such monitoring results (Figure 3c).

The results showed that the crack opening evolved with temperature variation. The opening of cracks ranged from $0.3 \mathrm{~mm}$ to $17 \mathrm{~mm}$. The tendency of the crack opening was correlated to the temperature, in terms of temperature increase leading to crack opening increase. This seems to be more correlated to the rock's drying process and its relation with the deformation under the drying path.

\section{Microscopic Features of the rock $U 3$ layer}

\section{Microscopic analysis}

Because the opening cracks were more localized in U3 layer, hereafter, only the samples extracted from this layer were considered for

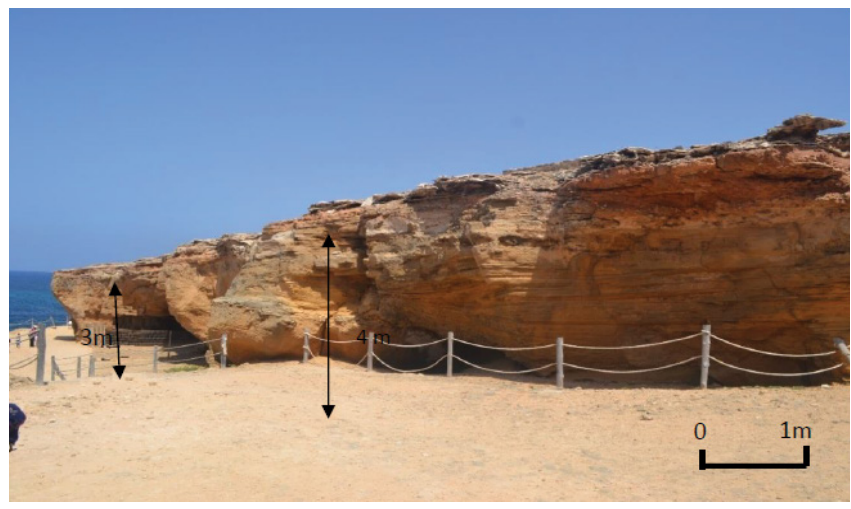

Figure 1: Real frontal view of the caves.
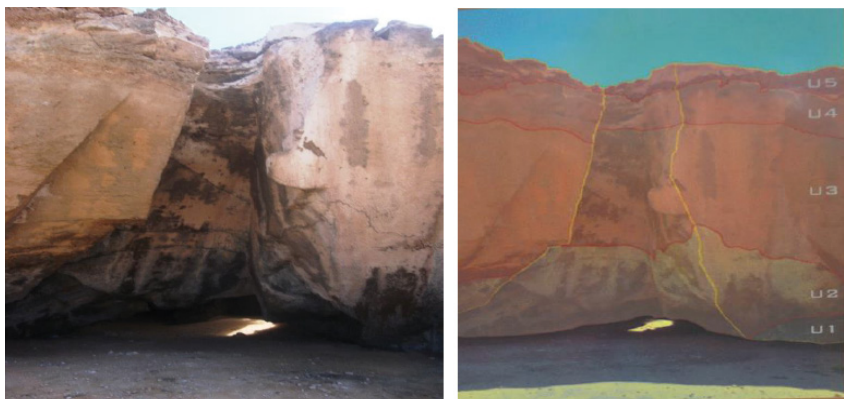

Figure 2: Geological limited layers. 
Citation: Koubaa Y, Jamei M, Guiras H (2018) Hydro-mechanical Properties of Highly porous Limestone Rock used for Historic Monuments in NorthEast Tunisia. J Civil Environ Eng 8: 310. doi: 10.4172/2165-784X.1000310

Page 3 of 11

the hydro-mechanical experimental program. Rock $U 3$ was examined through an optical microscope, a scanning electron microscope (SEM) and an X-ray diffraction technique in order to identify the texture, the micro- structural features and the mineralogical composition as well. Two representative samples from rock $U 3$ were extracted (U3-1-and $U 3$ 2), U3-1-and U3-2 are considered a subdivision of rock $U 3$ type. Each of the two subdivision layers is characterized by a corresponding specific porosity. For each U3-1-and U3-2 subdivisions, some optical microscopic tests where images under plane-polarized and cross-polarized light are taken are performed. Thin-section images of both samples are shown in Figure 4. The examination under the optical microscope reflects the following observations:

Rock U3-1 sample has a well-ranked and highly-porous grain-stone texture. The samples consist of limestone fossil debris and quartz grains. The grains are well cemented and some liaisons lining the inner and outer walls of certain elements were observed.

Rock U3-2 sample has a mixture of grain-stone and pack-stone texture. The samples consist of abundant pellets, limestone fossil debris and quartz grains.

The qualitative mineralogical composition of the tested rock
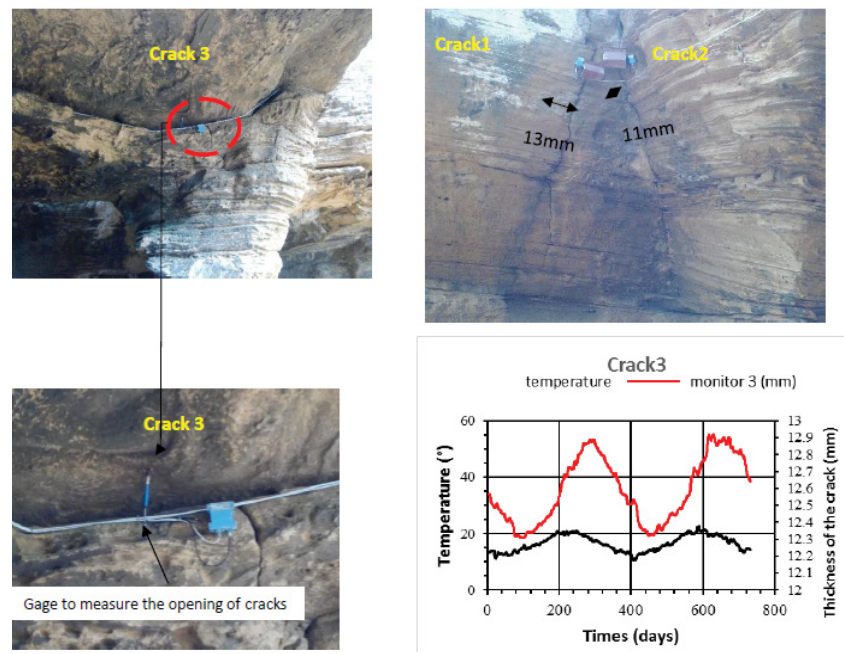

Figure 3: (a) Monitoring of the developed cracks; (b) The strain gauge placement; (c) A crack opening in parallel to the temperature variation during the time in days.
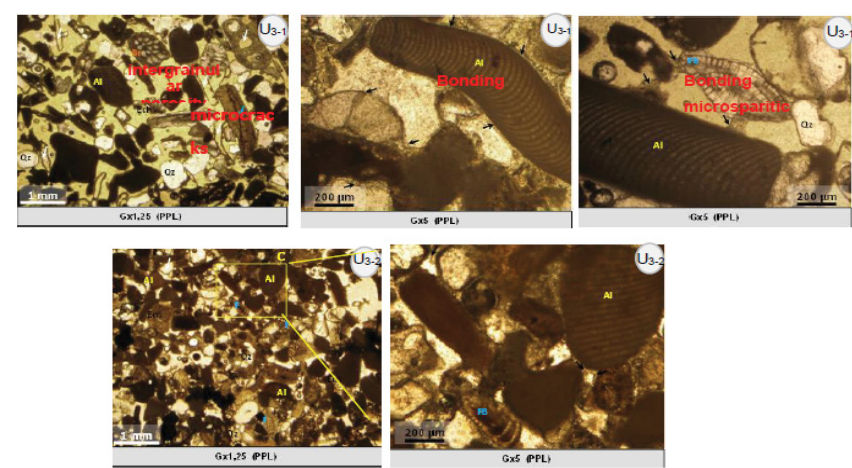

Figure 4: Thin sections $(1 \mathrm{~mm}$ and $200 \mu \mathrm{m})$ of the samples from U3 layers in plane polarized light U3-1: (AL: algae, QZ: Quartz, Br: Bryozoans, Ech: Echinoderms, F: Foraminifera, FB: Benthic Foraminifera, Gs: Gastropod, PI: peloids and Pellets). samples was identified by XRD diffraction (XRD) technique. The resultant obtained is given in the XRD diffractogram for U3-1 and U3-2 rock samples and is shown in Figures $5 \mathrm{a}$ and $5 \mathrm{~b}$. The major rock minerals from rock U3-1 and rock U3-2, are calcite $\mathrm{CaCO}_{3}, \mathrm{SiO}_{2}$ and some minority minerals such Aragonite, halite.

\section{Chemical and mineral analysis}

A chemical analysis was performed on two samples of rock $U 3$ types of 'El-Haouaria caves' (Table 1). To identify their texture, microstructural features and mineral composition, the rocks were examined by SEM and XRD techniques. It was shown that for the same mineralogical composition, the rock has a different porosity and a different grain size. Rock porosity varies from $25 \%$ to $55 \%$, and the grain-connecting cement is very fine, which can be considered as an indication that the rock in its two aspects may be classified as a tender rock.

\section{Binding between grains: The Scanning Electron Microscope (SEM)}

The binding and cemented character of the material was described based on two samples examined by a Scanning Electron Microscope (SEM). SEM analysis showed that cement was abundant and it covered almost all grains (Figures 6a and 7a). The cement is thin isopachous (thickness nearly of $35 \mu \mathrm{m}$ ), micritic to microsparitic surrounding grains (Figure $6 \mathrm{~b}$ ). The Cave rock area was formed during the early digenesis, ensuring the consolidation of the rocks (Figures $6 \mathrm{a}$ and $6 \mathrm{~b}$ ), while its inter-granular porosity was maintained. As It can be observed, the increased cement in inter-granular pores and the later filling of another quantity closes the gaps between the intra-granular pores (Figures $6 \mathrm{c}$ and $6 \mathrm{~d}$, Figure 7c), sealing locally the links between the inter-granular pores.

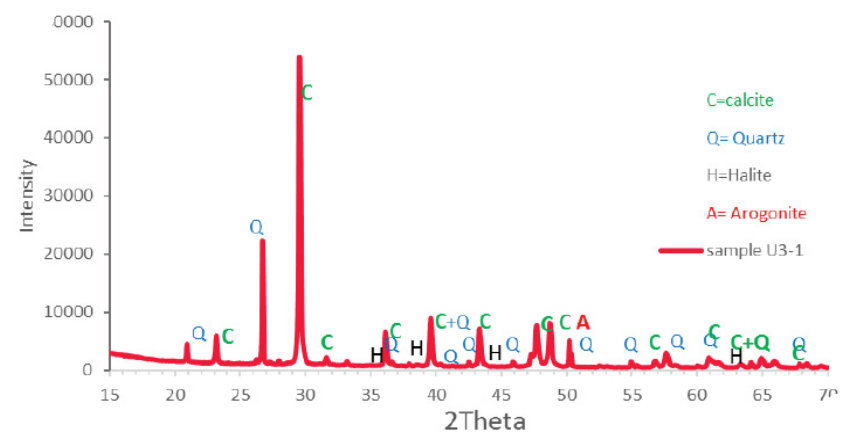

Figure 5a: Typical whole sample diffractogram of the sample U3-1 ( $(\lambda \mathrm{Cu}-\mathrm{K} \alpha 1=1,5406 \AA)$.

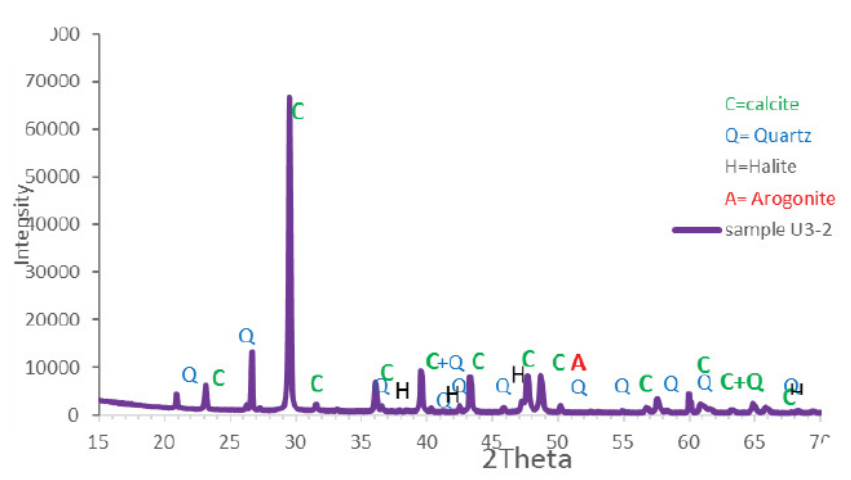

Figure 5b: Typical whole sample diffractogram of the sample U3-2 ( $\lambda \mathrm{Cu}-\mathrm{Ka} 1$ $=1.5406 \AA$ ). 
Citation: Koubaa Y, Jamei M, Guiras H (2018) Hydro-mechanical Properties of Highly porous Limestone Rock used for Historic Monuments in NorthEast Tunisia. J Civil Environ Eng 8: 310. doi: 10.4172/2165-784X.1000310

Page 4 of 11

This might be a new formation of cement. Rock degradation seems to be mainly caused by the humidity gradient and temperature variation. Humidity and temperature measurements in El-Haouaria caves are made by means of a hygrometer. These measurements have shown that humidity varies between $40 \%$ in August and $90 \%$ in February whereas temperature varies between $37^{\circ} \mathrm{C}$ in summer and $13^{\circ} \mathrm{C}$ in February because "El Haouaria" archaeological site is located on the seacoast, water is loaded with salts, thus causing the formation of salt layers of salt such as halite and aragonite as shown by the SEM (a) below.

\begin{tabular}{|c|c|c|c|}
\hline \multicolumn{2}{|c|}{ Variables } & U3-1 & U3-2 \\
\hline Quartz & $\mathrm{SiO}_{2}(\%)$ & 12.39 & 5.03 \\
\hline Alumina & $\mathrm{Al}_{2} \mathrm{O}_{3}(\%)$ & 0.26 & 0.16 \\
\hline Iron oxide & $\mathrm{Fe}_{2} \mathrm{O}_{3}(\%)$ & 0.62 & 0.16 \\
\hline Magnesium & $\mathrm{MgO}(\%)$ & 0.92 & 1.26 \\
\hline Potassium oxide & $\mathrm{K}_{2} \mathrm{O}(\%)$ & 0.04 & 0.07 \\
\hline Sodium oxide & $\mathrm{Na}_{2} \mathrm{O}$ & 0.05 & 0.88 \\
\hline Calcite & $\mathrm{CaO}(\%)$ & 47.1 & 50.5 \\
\hline Loss on heat (CO) & $\mathrm{PF}(\%)$ & 37.83 & 41.13 \\
\hline Sulfur trioxide & $\mathrm{SO}_{3}(\%)$ & $<0.01$ & $<0.01$ \\
\hline Total & $\mathrm{Total}^{(\%)}$ & 99.21 & 99.19 \\
\hline
\end{tabular}

Table 1: Chemical analysis.

(a)

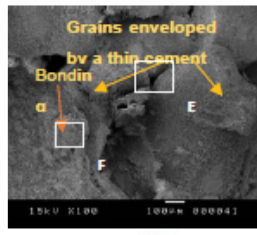

(d)

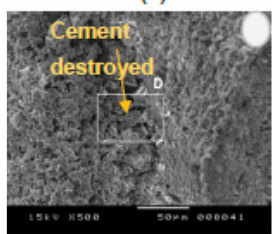

(g)

(b)

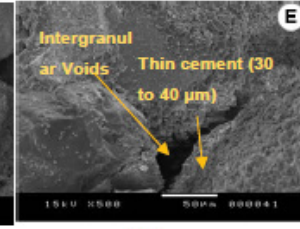

(e)

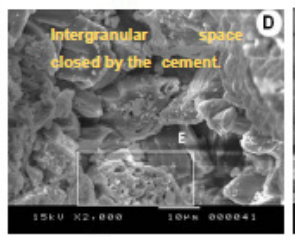

(h)

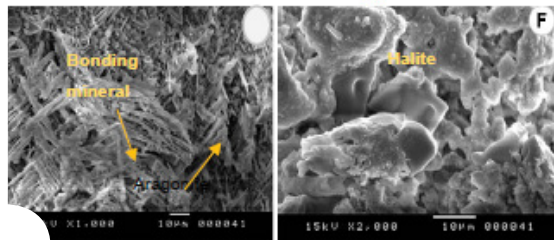

Figure 6: SEM micrographs of El Haouaria cave rocks U3-1; (a) Grains and bonding material (b) Voids (c) Microsparitic cement of another later-formed cement sealing the porosity (d) Cement destroyed (e ) intergranular porosity (f) Dissolution of same grains (g) A mineral having a fibrous appearance (Arogonite) (h) A cubic mineral (halite).
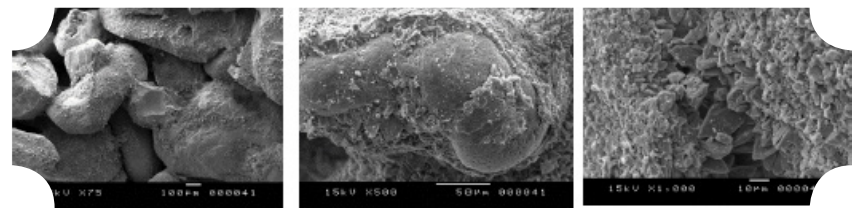

Figure 7: SEM micrographs of the caves EI Haouaria rocks U3-2; (a) Grains and bonding material and intergranular porosity (b) The lodges of a foraminifer partially covered by a fine cement of 10 to $20 \mu \mathrm{m}$ thick (c) Microsparitic cement of another later cement sealing the porosity.

\section{Macroscopic Hydro-Mechanical Features}

\section{Laboratory tests and objectives of the experimental study}

The study objectives consist in obtaining the strength characteristics of the rock $U 3$ and their dependency on both porosity and water content. Water content evolution and its effect on porosity were analyzed based on water retention curve and in relation with microscopic observations. Some hydraulic cyclic tests were performed in order to understand the evolution rock porosity.

To perform laboratory tests, rock samples were extracted from layer U3 (Figure 2). Large blocks of rocks have been cut from the 'El-Haouaria caves' and prepared to undergo all the hydraulic and mechanical tests.

To obtain the uniaxial compressive strength of rock $U 3$ two types of tests were performed. The first type of test is carried out at a controlled force. The second series of simple compression tests were performed at a controlled displacement. The samples were obtained by water drilling method and cutting disc in the end.

For rock $U 3$ tensile strength, two types of tests were performed three - point bending tests and splitting tests. For the first type, samples were obtained by using a cutting disc and having a parallelepiped shaped forms with a $40-\mathrm{mm}$ width of and a $160-\mathrm{mm}$ height. For the second type, the samples were prepared in a cylindrical shape (of a 100$\mathrm{mm}$ diameter and a 200- $\mathrm{mm}$ height).

In order to obtain the required cylindrical specimens, a rotary coring method was applied. The thickness was trimmed by cutting with a disc in the laboratory. Specimens from the block samples were prepared by manual trimming in both ends. Their parallelism was measured repeatedly using a water-pass, until obtaining parallel end surfaces free from asperities. The rock samples are made according to a stratification parallel to the rock base.

\section{Testing procedures}

Firstly, dry unit weights and specific gravity were determined for rocks U3. The Uniaxial Compressive Stress tests (UCS) were conducted on dried and saturated, samples. 9 specimens with $10 \mathrm{~mm}^{\star}, 10 \mathrm{~mm}^{*}$, $20 \mathrm{~mm}$ dimensions, and 50 specimens having $4 \mathrm{~mm}^{\star}, 4 \mathrm{~mm}^{\star}, 8 \mathrm{~mm}$ dimensions were prepared from block samples. The UCS tests were carried out according to French Standard NF P 94-420. The water content was measured by using pieces of the rock taken from Unit $U 3$.

The compression tests were carried out by using a uniaxial compression test device with a maximum load capacity of $300 \mathrm{kN}$ for one sample and a uniaxial compression test device with a maximum load capacity of $3000 \mathrm{kN}$. Loads were applied at a fixed displacement rate of $0.5 \mathrm{~mm} / \mathrm{min}$. This rate resulted in a specimen failure within 5 min to $7 \mathrm{~min}$. For rock $U 3$ type, compression tests were carried out at a dry and saturated state under uniaxial conditions. Samples were drilled from large block samples extracted from the nearby surface quarries out of the collapsed block of ancient quarries.

Three bending tests were performed for the measurement of the tensile strength. The sample was placed on two supports. Considering that a rock's tensile strength is unequal to its compressive strength, the sample will break as soon as the rock will reach its limit tensile strength. The limit stress resulting from the design strength of materials is $\sigma_{\mathrm{tf}}$ as a limit elasticity (flexural tensile stress, noted $\square_{\mathrm{t}}$ in hereafter). The threepoints bending test was performed with a press having a loading rate of $0.05 \mathrm{~mm} / \mathrm{min}$, so that failure takes place between $2 \mathrm{mn}$ and $10 \mathrm{~min}$ after the start of loading (depending on sample porosity and heterogeneity). The Brazilian test was carried out with the same press as that of the 
uniaxial compression strength but at a lower speed so that the tensile strength is reached after a test time exceeding $2 \mathrm{~min}$.

A total of 60 cube-shaped specimens $25 \mathrm{~mm}$ wide were trimmed from undisturbed block samples. The suction of $U 3$ rock samples was applied and/or determined by using two complementary techniques: the osmotic method and the salt solution method. Two paths were followed: the wetting (i.e., humidification) path and the drainage path. To obtain the water retention curve for the wetting path, the samples were dried in advance in an oven at $105^{\circ} \mathrm{C}$ for 24 hours.

The osmotic method, used for suction less than $1500 \mathrm{kPa}$, consists in placing the sample in a semi-permeable membrane which separates the sample from the polyethylene glycol solution (PEG), prepared at a well-defined concentration. A chemical potential difference between the water within the sample and The PEG solution is created by causing water exchange between the two areas until reaching an equilibrium [41].

On the other hand, the saline solution technique consists in placing the sample in desiccators, under a differently relative humidity, maintained by saturated salt solutions [42]. After that, the samples were weighted at regular intervals. To reach the hydraulic equilibrium, it needs approximately 2 weeks. For each relative humidity value, the water content was determined by measuring the sample weight at the end of each test. However, water retention corresponding to the drying path was followed starting from a full saturated state, and the same techniques to obtain the suction, as explained previously, were used. Analyzing the obtained results, two ranges of porosity were defined and the water retention curves were obtained.

In order to investigate the drying-humidification cycle, 10 samples were subjected to 10 drying and wetting cycles until saturation. Drying of the samples was carried out in an oven $100 \mathrm{C}^{\circ}$ for 48 hours and wetting to reach saturation was carried out by imbibing by water at a constant temperature during one week. The samples were placed in vacuum dryers.

\section{Results and Discussion}

\section{Physical properties}

The ranges and mean values of the physical properties of the rock samples are given in Table 2. Low dry unit weight and high porosity values were obtained in this study.

The pore size distribution (Figure 8 ) indicated the mono-modal character of the rock $U 3$ (porosity $32 \%$ ) and the dominant diameter of the pore is around $3 \mu \mathrm{m}$.

\section{The water retention curve}

The obtained water retention curve is presented in Figure 9, which clearly shows that water adsorption increases with the decrease of suction. The hysteretic behavior is clearly shown, and this indirectly demonstrates the role of internal porosity distribution. Indeed, for high suctions, this rock has an extremely low water content, probably generated only by adsorption. Then when suctions become very low, the capillary forces of the majority of the stone pores are then sufficient to capture and retain water. And it is interesting to note that even with only $0.1 \mathrm{MPa}$ suction (lower suction imposed by the osmotic method), the rock of the caves cannot fully saturate, which shows the importance of macro-porosity of the stone in El-Haouaria caves. And again, when looking at the sorption-desorption curves, we note that desorption (drainage) in water levels is still higher than the sorption (humidification) with a well-marked hysteresis presence for suctions in a range between $10 \mathrm{kPa}$ (low suction) and $2000 \mathrm{kPa}$. In general, the average air-entry value suction is estimated approximately at $50 \mathrm{kPa}$ for the drainage path and at $30 \mathrm{kPa}$ for the humidification path. Naturally, the more the porosity is, the less the air-suction entry value is.

The hydraulic hysteresis behavior was observed for other rocks by $[43,44]$. The physical explanation of the phenomenon of hydraulic hysteresis results from micro- structural considerations of the irreversible movement of the air-water interface during the wetting and drying process $[45,46]$.

Therefore, the features of WRC depend on rock properties such as type of constituent grains, mineralogy, particle size distribution, rock structure (arrangement of particles or/and aggregates) and porosity as well as on the path of water content changes (wetting and drying) $[47,48]$.

In this study, the effect of porosity was well identified in Figure 9, to get the results of two ranges of porosity variation (average porosity varies approximately from $30 \%$ to $40 \%$ and then from $40 \%$ to $55 \%$ ). As it was demonstrated by Figure 9, porosity strongly affected the hydraulic behavior in terms of both wetting and drying features. The Van Genuchten model was fitted in order to obtain the curves as it was depicted for the two ranges of porosity. Table 3 summarizes the parameters of the van Genuchten model [49], corresponding to the plotted curves in Figure 9.

\begin{tabular}{|c|c|c|}
\hline Physical characteristics & U3-1 & U3-2 \\
\hline Bulk density $\left(\mathrm{g} / \mathrm{cm}^{3}\right)$ & $2.1-2.5$ & $1.5-1.7$ \\
\hline Solid density $\left(\mathrm{g} / \mathrm{cm}^{3}\right)$ & 2.73 & 2.73 \\
\hline Porosity & $25 \%$ to $35 \%$ & $36 \%$ to $55 \%$ \\
\hline
\end{tabular}

Table 2: Physical properties of the tested rocks.

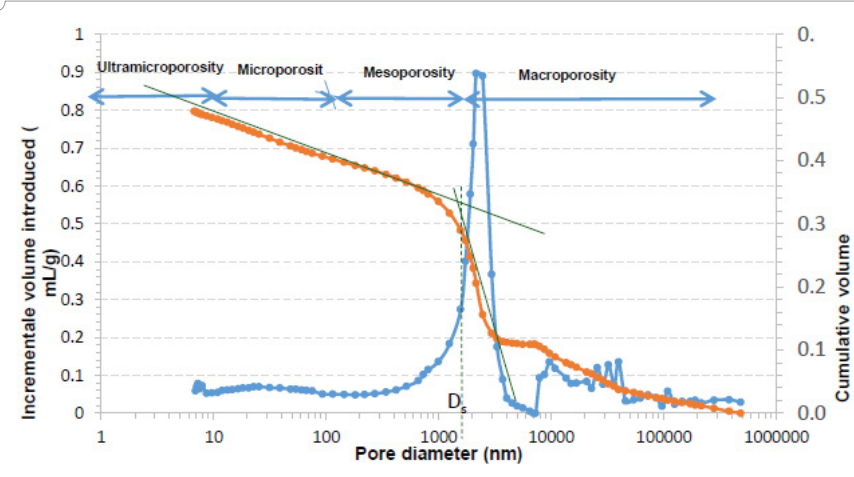

Figure 8: Pore size distribution of rock U3.

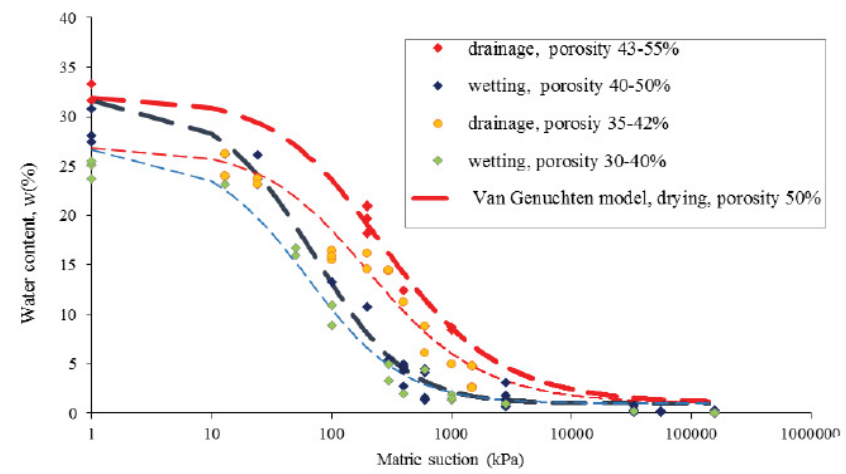

Figure 9: Water retention curve of unit rock U3. 


$$
\theta=\theta_{r}+\theta_{s}\left(\frac{1}{\left(1+(\alpha S)^{n}\right)}\right)^{m}
$$

Where $\theta$ is the water content $\left(\mathrm{cm}^{3} \cdot \mathrm{cm}^{-3}\right) ; S$ is the suction $(\mathrm{kPa}) ; \theta_{s}$ is the water content at saturation $\left(\mathrm{cm}^{3} \cdot \mathrm{cm}^{-3}\right) ; \theta_{r}$ is the residual water content $\left(\mathrm{cm}^{3} \cdot \mathrm{cm}^{-3}\right) ; \alpha$ is related to the inverse of the air entry suction $\left(\mathrm{cm}^{-1}\right) ; n$ and $m$ are the shape parameters of soil water characteristic.

As it is known, in geotechnical field, the effect of the structure and void ratio on the water storage capacity of a given soil has been highlighted in several experimental investigations [50,51]. As pointed out by several authors [52-54], the water retention curve is well dependent on compaction and consequently on porosity distribution (micro and macro porosity).

\section{Effect of hydraulic cycles}

In order to investigate the humidification impact on porosity variation, some wetting- drying tests were applied. Indeed, Table 4 presents hereafter the variation of the total porosity after 10 hydraulic

\begin{tabular}{|c|c|c|c|c|c|c|}
\hline \multirow{2}{*}{ Path } & \multirow{2}{*}{ Porosity (\%) } & \multirow{2}{*}{$q_{r}$} & \multirow[b]{2}{*}{$q_{s}$} & \multicolumn{3}{|c|}{ Model parameters } \\
\hline & & & & a & $\mathbf{n}$ & $\mathbf{m}$ \\
\hline \multirow{2}{*}{ Wetting } & $50 \%$ & 1 & 32 & 0 & 2 & 0.8 \\
\hline & $38 \%$ & 1 & 32 & 0 & 1 & 0.6 \\
\hline \multirow{2}{*}{ Drying } & $50 \%$ & 1 & 27 & 0 & 1 & 0.7 \\
\hline & $38 \%$ & 1 & 27 & 0 & 2 & 0.8 \\
\hline
\end{tabular}

Table 3: Value of the Van Genuchten model parameters according to humidification and drainage.

\begin{tabular}{|c|c|c|c|}
\hline \multirow{2}{*}{ Samples } & Initial porosity $\mathbf{F}_{\mathbf{1}}$ & $\begin{array}{c}\text { Porosity after 10 cycles } \\
\text { Wetting-Drying, } \mathbf{F}_{\mathbf{2}} \mathbf{( \% )}\end{array}$ & \multirow{2}{*}{ F1- F2 } \\
\hline 1 & $\mathbf{( \% )}$ & $48 \%$ & $7 \%$ \\
\hline 2 & $41 \%$ & $46 \%$ & $8 \%$ \\
\hline 3 & $38 \%$ & $39 \%$ & $10 \%$ \\
\hline 4 & $29 \%$ & $42 \%$ & $13 \%$ \\
\hline 5 & $30 \%$ & $46 \%$ & $6 \%$ \\
\hline 6 & $40 \%$ & $48 \%$ & $8 \%$ \\
\hline 7 & $40 \%$ & $47 \%$ & $11 \%$ \\
\hline 8 & $36 \%$ & $43 \%$ & $12 \%$ \\
\hline 9 & $31 \%$ & $44 \%$ & $10 \%$ \\
\hline 10 & $35 \%$ & $41 \%$ & $13 \%$ \\
\hline 11 & $28 \%$ & $42 \%$ & $14 \%$ \\
\hline 12 & $28 \%$ & $47 \%$ & $12 \%$ \\
\hline & $35 \%$ & & \\
\hline
\end{tabular}

Table 4: Porosity variation after 10 hydraulic cycles.

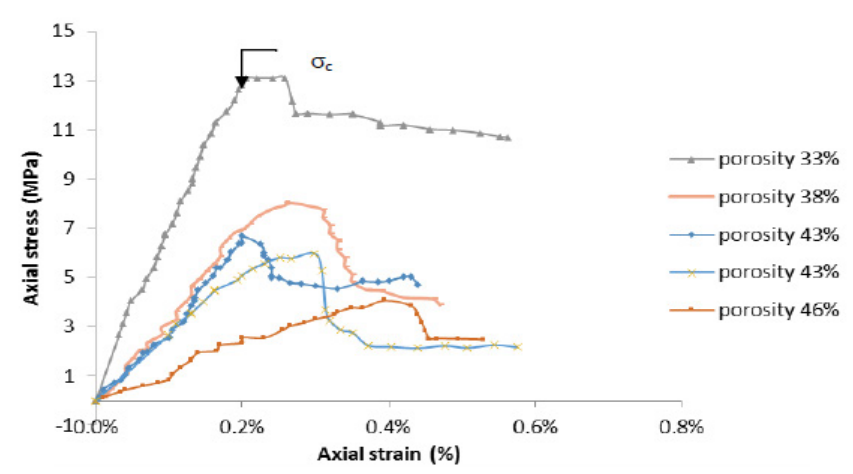

Figure 10: Compression Stress-strain curves of rock $U 3$ in the dry state for several porosities. cycles. Porosity variation was in the range of $6 \%$ - $14 \%$. It seems that the variation was more important for the samples with low initial porosity (more cementation rates of the grains). This result can be attributed to the effect of the wetting path on the cementation between grains, in the sense that the cementation vanished during the wetting-drying cycles.

Compression tests were performed on a series of $6 U 3$ specimens. The tests were conducted in the two extreme water conditions: dry (after 24 hours in an oven at $105^{\circ} \mathrm{C}$ ) and saturated (vacuum impregnation with water and aerated soaking for 24 hours). Representative stress-strain curves for six of the samples were presented in Figure 10 and Figure 11. The curves are initially less concave, followed by a quasi-linear elastic stage. The curves then show a strain hardening stage before reaching a peak stress $\left(\sigma_{p}\right)$. Finally the failure of the rock corresponds to the drop of the stress. UCS varies between $13 \mathrm{MPa}$ for the porosity of $33 \%$ to 4 $\mathrm{MPa}$ for porosity of $46 \%$ (reference dry state) for the rock $U 3$, which is characteristic of soft rocks [55]. As a first conclusion, this low strength is obviously controlled by the material's high porosity.

A second conclusion concerns the important reduction in compressive strength measured on saturated specimens compared to that measured on dry samples. The higher the water content of the rock is, the more deformations during compression it undergoes.

Water presence plays a significant role in UCS between a dry state and a saturated state, strength loss reached $50 \%$ for rock $U 3$. So, the presence of water in the pores of the rock leads to a reduction of the mechanical strength. And this can be explained by a decrease of the contact surface between the constituent grains and, therefore, a modification of the inter-granular links [56].

The trend of the stress-strain curves under uniaxial compression loading can be identified to the results as found for other types of rocks [57-59]. The UCS results were summarized in a plot of UCS versus porosity in Figure 12. The general trend is that UCS decreases (from 14 $\mathrm{MPa}$ to $1.2 \mathrm{MPa}$ ) while total porosity increases.

To quantify the effect of the suction (or the water content) some uniaxial compression tests were performed under controlled suction. Rock specimens were equilibrated at various capillary suctions using two techniques applied for water retention curve (saturated salt solutions and osmotic solutions). The U3 rock samples were tested under a uniaxial compression test from saturated to dry states, and under applied suctions $100 \mathrm{kPa}, 400 \mathrm{kPa}, 600 \mathrm{kPa}, 1000 \mathrm{kPa}$ and 1500 $\mathrm{kPa}$. Figure 13 shows the UCS against average porosity for several applied suctions. It can be observed that the compression strength is globally slightly affected by water content variation (from dry to saturated state) compared to the influence of porosity.

One can clearly observe two different trends of the compressiondisplacement curves at the same porosity (porosity is considered the same for $\pm 2 \%$ ). The cause of this difference may be attributed to a variation in the microstructure of the samples. More precisely, the cementation which connects the grains develops more or less resistance after the pick of the compression stress. The more the cementation is, the more the resistance at its maximum level is. In fact, at a saturation state, the more the porosity is the more the softening feature is emphasized. At an average similar porosity, the softening character is not appeared in the case of dried samples.

All compression tests show that the variation in porosity for rock resistance has an impressive effect, which exceeds the effect of water content on rock resistance (Figure 12).

Under applied suctions using several methods (as described above in section 4.2), samples were prepared and tested under compressive 
tests. The results in terms of compressive strength are presented in Figure 13. It appears that rock behavior for suction for more than 300 kpa is equivalent to that of a dry rock as shown in Figure 10. Prick defined a hydraulic softening coefficient obtained from the difference between the UCS corresponds respectively to a steady state and a dry state. This coefficient gives an initial estimation of the stone durability [60].

It can be identified as following: $\alpha_{\mathrm{s}}=\left(\mathrm{UCS}_{\mathrm{dry}}-\mathrm{UCS}_{\text {saturated }} / \mathrm{UCS}_{\mathrm{dry}}\right)$

The less the coefficient, the more the durability of the rock, in the sense that its resistance is not affected by humidification and, as a consequence, the UCSsaturated is approximately the same as the $\mathrm{UCS}_{\mathrm{dry}}$. In this case, the durability of rock $U_{3}$ is not yet significant (the average value of $\alpha_{s}$ is approximately 0.5 ).

\section{Tensile strength}

Two types of indirect tensile tests were performed: the splitting tests and the three - point bending tests. In fact, the splitting tests (Brazilian tests) were performed on a series of 3 specimens. The tests were conducted in both extreme hydraulic conditions: dry (after 24 hours in an oven at $105^{\circ} \mathrm{C}$ ) and saturated (vacuum impregnation with water and aerated soaking for 24 hours). Representative stress-strain curves for 3 of the samples were presented in Figure 14 and Figure 15. The curves then show a strain hardening stage before reaching a peak stress $\left(\sigma_{t}\right)$. Tensile strength in Brazilian tests varies between $4 \mathrm{MPa}$ for a porosity of rock $39 \%$ to $2.5 \mathrm{MPa}$ for $41 \%$ (reference dry state). The tensile elastic modulus was $0.24 \mathrm{GPa}$ with a porosity of $39 \%$. Hence,

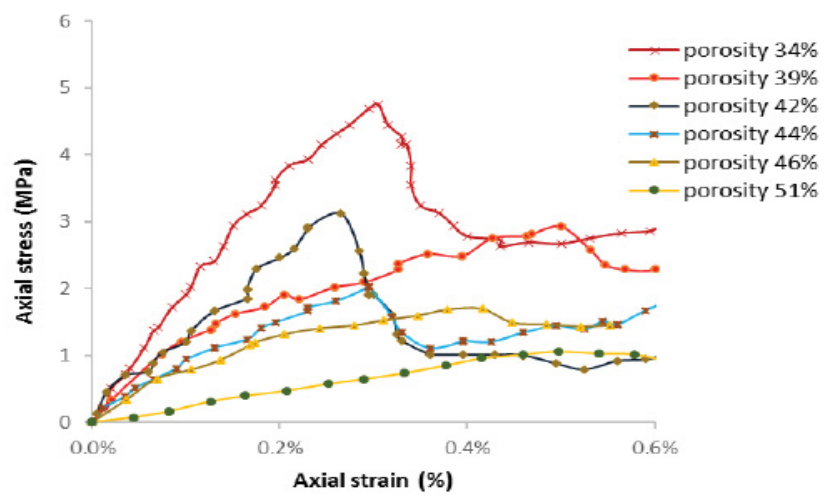

Figure 11: Compression stress-strain curves of rock $U 3$ in a saturated state for several porosities.

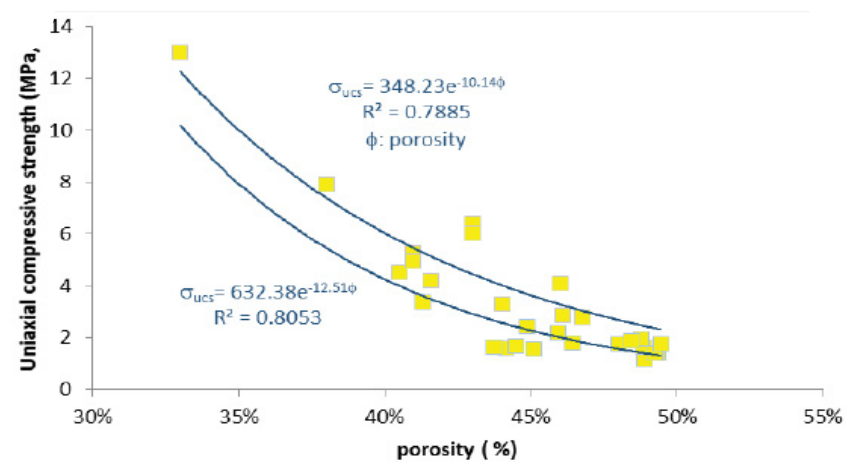

Figure 12: The uniaxial compression strength against the total porosity, dry state.

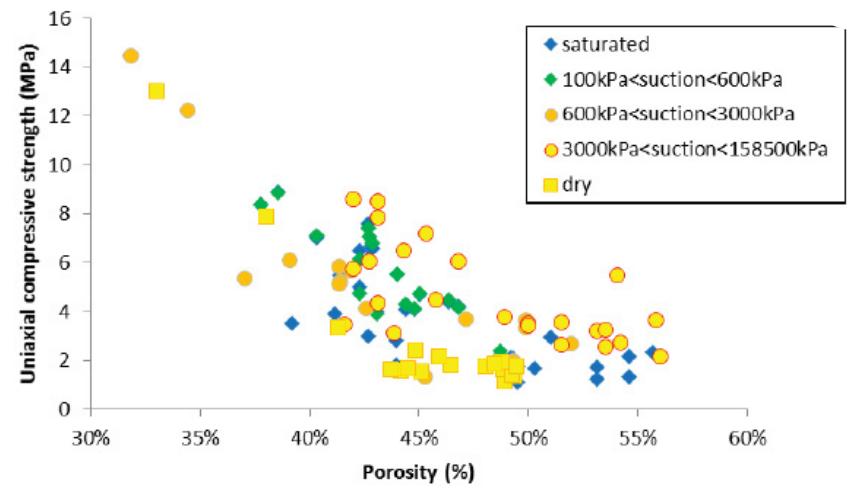

Figure 13: Uniaxial compressive strength (peak stress) against total porosity for different suctions.

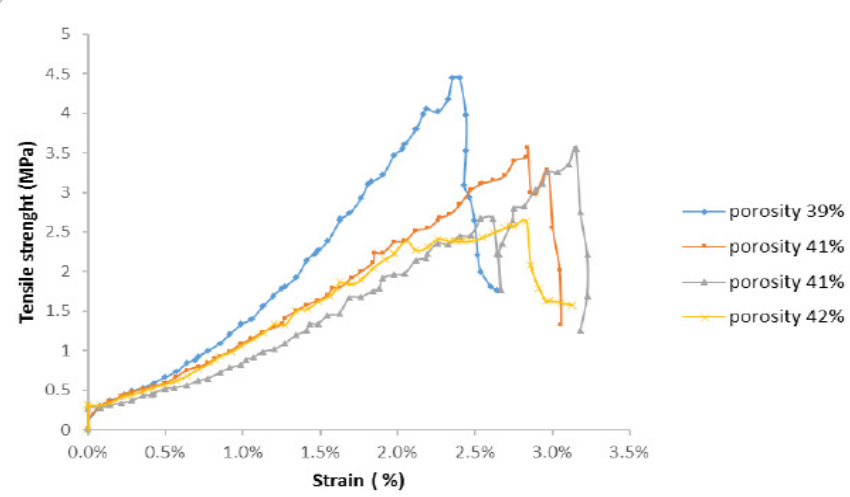

Figure 14: Tensile stress-strain curves of rock U3 in dry state for severa porosities.

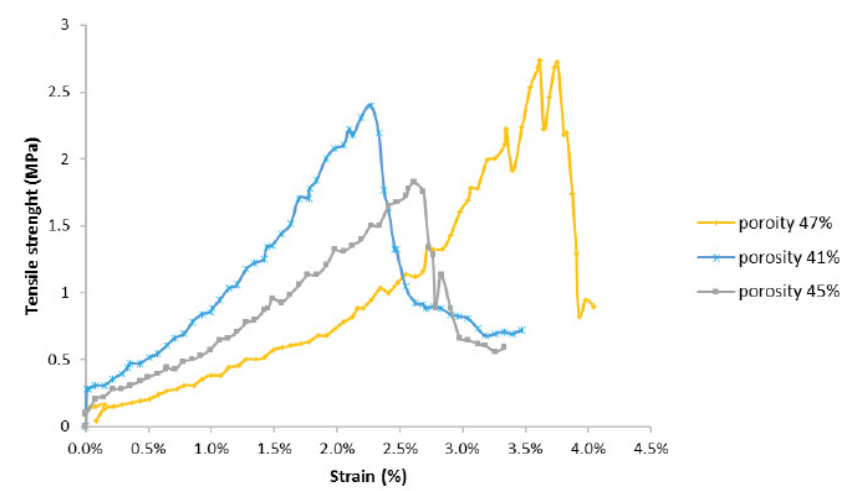

Figure 15: Tensile stress-strain curves of rock U3 in the saturated state for several porosities (saturated state).

the low tensile Young's modulus indicates the bi-modular character of such rock. One second finding conclusion is the significant reduction in tensile strength measured on saturated specimens compared to that measured on dry samples.

Measuring the indirect tensile strength by the three -point bending test was performed under the same experimental conditions as for the uniaxial compression tests. The samples have parallelepiped shaped forms with a $40-\mathrm{mm}$ edge and a $160-\mathrm{mm}$ height. Figure 16 shows the variation of the tensile strength determined by the three-point bending 
tests for different controlled water contents and with the variation of the total porosity. Such tests showed an important decrease of the tensile strength while porosity increases. Figure 17a shows the tensile strength evolution in the case of totally dried samples. Figure $17 \mathrm{~b}$ corresponds to the fully-saturated samples. This Figure also shows the role of the heterogeneity of the extracted natural rocks. The tensile strength is between $0.7 \mathrm{MPa}$ and $0.2 \mathrm{MPa}$ (reference dry), which is also a common characteristic of soft rocks [61]. This value corresponds to about $10 \%$ of the compressive strength, which is usual for rocks [62]. Tables 5 and 6 summarize the tensile characteristics of the rock $U 3$ separately for dry and saturated states.

Added to the main role of the porosity on tensile strength, followed by the role of the water content (suction), Figure 17 shows again the significant effect of the rock heterogeneity mainly characterized by the variation existing in the microstructure of the samples. This variation is mainly displayed in the cementation connecting the grains. Like the compressive future, the measured tensile strength significantly decreases with the water content (comparison between saturated state and dry state). Porosity also plays an important role in the tensile resistance of the material.

The rate between compression strength UCS and tensile strength UTS (given by the three-point bending tests ) for such tested rocks decreases from the average values 5 to 1 when the porosity increases from $20 \%$ to $48 \%$ for the completely dried samples and from 2 to 1 for the full saturated samples. Figure 16 shows the evolution of the rate between compression strength and tensile strength.

Finally, the effect of suction on tensile strength was investigated (Figure 18). As it is shown in this Figure, the effect of porosity on tensile strength is also dominant compared to the role of suction. The variety of tensile strength values can be explained in part by the variety of mineralogical composition and micro- defect distribution (microporosity and micro-cracks) in the naturally extracted samples, in the sense that it was naturally impossible to have exactly the repetitive same sample with a same microstructure.

\section{Modeling of the Experimental Results using the " $\mathrm{Li}$ and Aubertin's" Model}

The aim of this section is to test one of the published models to reproduce the obtained experimental study in order to prepare a suitable model so as to obtain a numerical monitoring procedure of the cave structures. In fact, we used Li and Aubertin's model [63] already published to predict the rock's uniaxial compression (UCS) and uniaxial tension (UCS) as of the porosity functions.

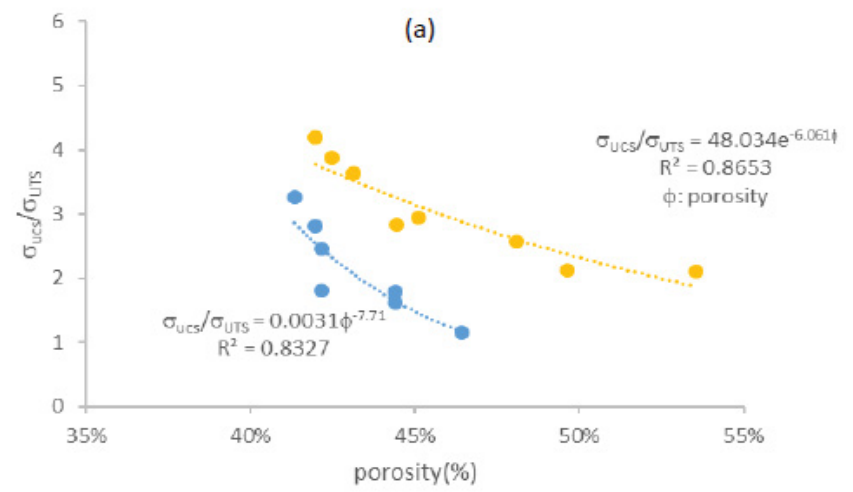

Figure 16a: The tensile strength evolution against the porosity for different samples (Dry state).

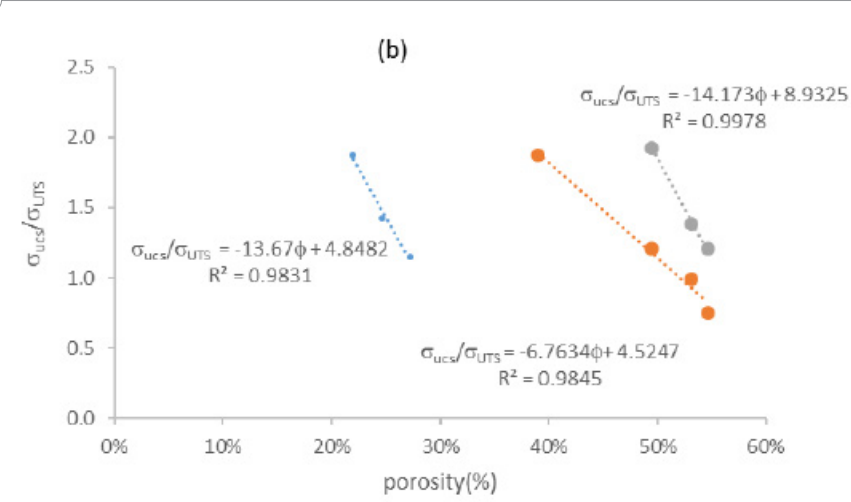

Figure 16b: The tensile strength evolution against the porosity for different samples (saturated state).

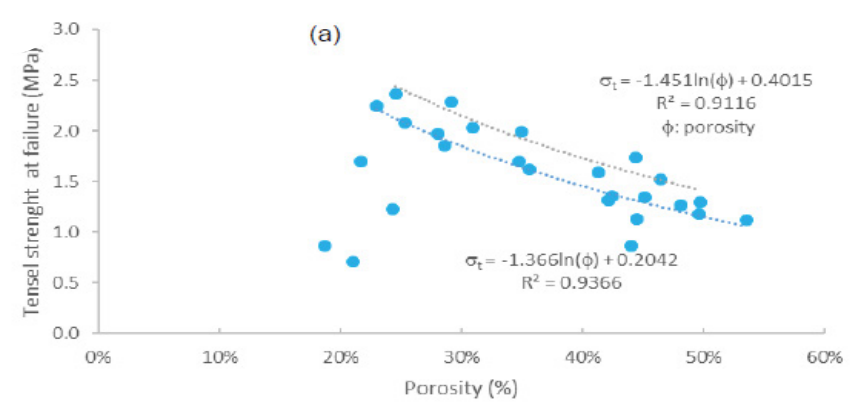

Figure 17a: The rate between compression strength and tensile strength against porosity for different samples (Dry state)

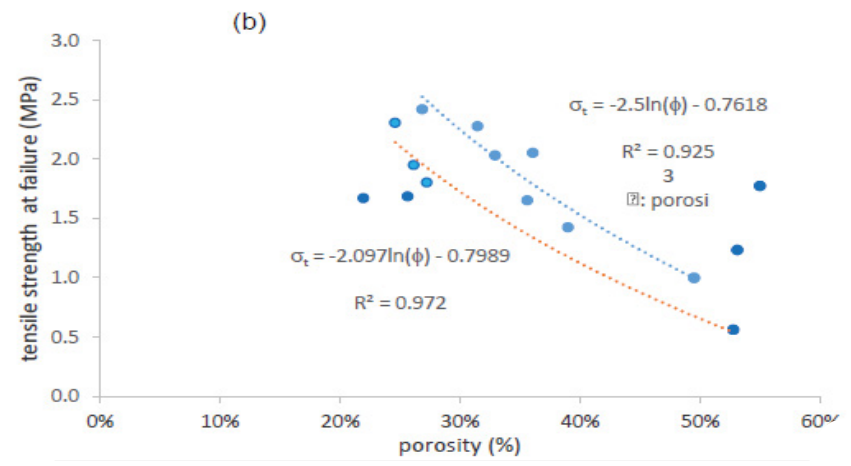

Figure 17b: The rate between compression strength and tensile strength against porosity for different samples (saturated state).

The equation Li and Aubertin is as follows:

$$
\sigma_{u n}=\left\{\sigma_{u 0}\left[1-\sin ^{\mathrm{x}_{1}}\left(\frac{\pi \phi}{2 \phi_{c}}\right)\right]+\left\langle\sigma_{u 0}\right\rangle \cos ^{x_{2}}\left(\frac{\pi \phi}{2 \phi_{c}}\right)\right\}\left\{1-\frac{\left\langle\sigma_{u 0}\right\rangle}{2 \sigma_{u 0}}\right\}
$$

Where $\sigma_{u n}$ is the uniaxial resistances as a porosity function, if the resistance is compression ( $\sigma_{u n}=\mathrm{UCS}$ ), and if it is of tension ( $\sigma_{u n}=\mathrm{UTS}$ )

$\phi_{c}:(\leq 1)$ is the critical porosity at which $\sigma_{u n}=0$ (in tension $\phi_{c}=\phi_{\mathrm{Ct}}$ and in compression $\phi_{\mathrm{c}}=\phi_{\mathrm{Cc}}$ );

$\sigma_{u 0}$ is the resistance at $\phi=0$.

$\mathrm{x}_{1}$ and $\mathrm{x}_{2}$ : parameters of the material, 
Citation: Koubaa Y, Jamei M, Guiras H (2018) Hydro-mechanical Properties of Highly porous Limestone Rock used for Historic Monuments in NorthEast Tunisia. J Civil Environ Eng 8: 310. doi: 10.4172/2165-784X.1000310

Page 9 of 11

\begin{tabular}{|c|c|c|}
\hline Porosity & Tensile strength $\mathbf{( M P a )} \boldsymbol{\sigma}_{\text {UTS }}$ & Young's modulus (GPa) \\
\hline $39 \%$ & 4.4 & 0.24 \\
\hline $41 \%$ & 3.4 & 0.1 \\
\hline $41 \%$ & 3.5 & 0.1 \\
\hline $42 \%$ & 2.6 & 0.092 \\
\hline
\end{tabular}

Table 5: Tensile Stiffness of rock U3 in dry state (Tensile stress).

\begin{tabular}{|c|c|c|}
\hline Porosity & Tensile Strenght $\mathbf{s}_{\text {UTS }}(\mathbf{M P a})$ & Tensile Stiffness $\mathbf{( G P a )}$ \\
\hline $41 \%$ & 2.31 & 0.1 \\
\hline $45 \%$ & 2.1 & 0.04 \\
\hline $47 \%$ & 1.8 & 0.07 \\
\hline
\end{tabular}

Table 6: Tensile Stiffness of rock U3 in saturated state (Tensile stress).

\begin{tabular}{|c|c|c|c|c|c|}
\hline Variables & $\begin{array}{c}\text { Rock } \\
\text { classification }\end{array}$ & $\boldsymbol{x}_{\mathbf{1}}$ & $\boldsymbol{x}_{\mathbf{2}}$ & $\mathbf{s}_{\mathrm{u} 0}$ (MPa) & $\mathbf{f C c}$ and $\mathbf{f C t}$ \\
\hline $\begin{array}{c}\text { Compression } \\
\text { strength }\end{array}$ & U3-1 U3-2 & 1.15 & 13 & 140 & 0.57 \\
\cline { 1 - 5 } & 0.8 & 11 & 140 & 0.55 \\
\hline $\begin{array}{c}\text { Tensile } \\
\text { strength }\end{array}$ & U3-1 U3-2 & 1.6 & & -10.8 & 0.64 \\
\hline & 1.7 & & -3.7 & 0.65 \\
\hline
\end{tabular}

Table 7: Parameters of the Li and Aubertin model.

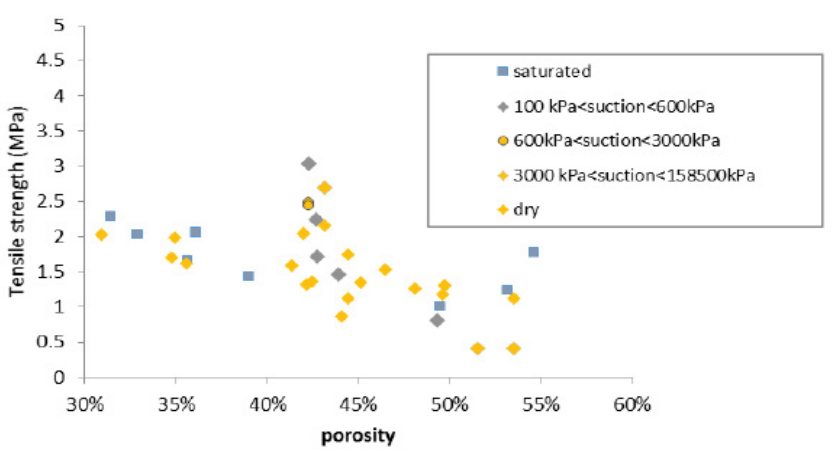

Figure 18: The tensile strength evolution against the porosity for different suctions.

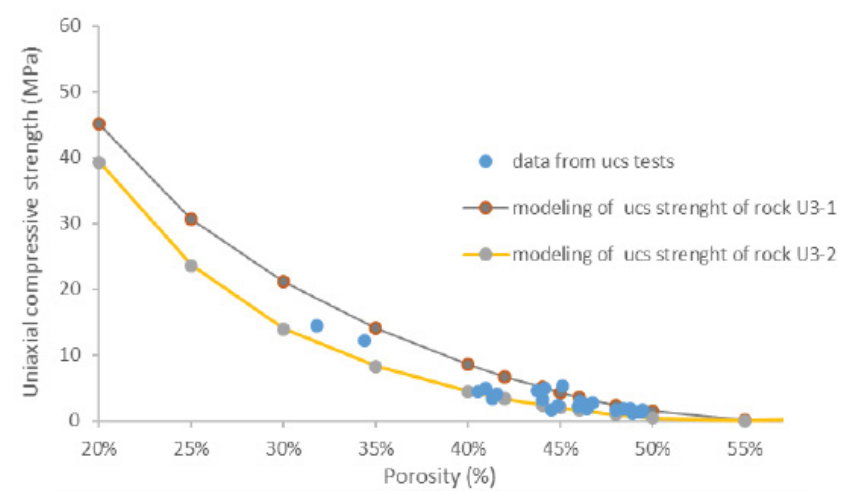

Figure 19: Modeling of the compression curve as a function of the porosity.

$<>$ are the Mac Cauley brackets $=(\mathrm{x}+|\mathrm{x}|) / 2)$.

The tensile stress, $\sigma_{\mathrm{un}} \leq 0,<\sigma_{\mathrm{u} 0}>=0$.

$\sigma_{u n}=U T S=\sigma_{t 0}\left[1-\sin ^{x_{1}}\left(\frac{\pi \phi}{2 \phi_{C t}}\right)\right]$
The parameters of Li and Aubertin model applied to rock U3 were determined by referring to the experimental data obtained in this study. The following Table 7 summarizes the obtained parameters.

As it is shown in Figures 19 and 20, the Li and Aubertin model reproduce the compressive and tensile strengths trends with porosity increase. The parameters of such model were identified and they can be used later to the modeling of the cave's structure. However, for the formation of $U 3-1$, the model's capability to reproduce tensile strength results for low porosity does not seems to be demonstrated. This can be explained by the difficulty to find samples from U3- 1 having porosity in the range of low values (less than $40 \%$ ).

\section{Analysis}

Rock $U 3$ hydro mechanical behavior aims to give some quantitative relations of the strengths and stiffness evolutions with the water content as a variable parameter and the water's effect on porosity due to the environmental cycles. Porosity increase is retained as a key parameter linked to the strength decrease.

The investigation of the microstructure of the limestone rock U3 provided from the monument of El-Haouaria caves shows the rock's mineralogy which is primarily made of calcite and quartz. The grains are of marine origin with a variable shape inducing a variable porosity. The cement connecting the grains is very fine and porosity is a very important sign confirming that the rock is indeed a soft rock. Rock porosity varies from one sample to another (U3.1-U3.2), and it has undergone changes over time by the presence of cements. This modification is caused by the dissolution of mineral salts present in the rock or coming from seawater (crystallization, presence of halite ...). From water retention curve, it was shown that the saturation water content is well dependent on porosity. Air entry value is very low, which is sign of absence of clay. The grains of the rocks have a coarse dimension equivalent to the sand. The shape of the retention curve is closely related to porosity. The curve showed the rock's hysteretic behavior ock, which can be explained by the role of porosity.

The results of the mechanical tests conducted on the limestone rock samples show the important influence of porosity on both, compression strength and tensile strength as well as on stiffness. At dried conditions, compression strength varies from $14 \mathrm{MPa}$ for $33 \%$ porosity to $4 \mathrm{MPa}$ for $48 \%$ porosity. However, at saturated conditions, the compression strength varies from $4.5 \mathrm{MPa}$ for $34 \%$ porosity to $2 \mathrm{MPa}$ for $44 \%$ porosity. The results show that the degree of critical saturation causing rock strength reduction is around $95 \%$ for the whole range of rock porosities. We conclude that the significant effect of the water content

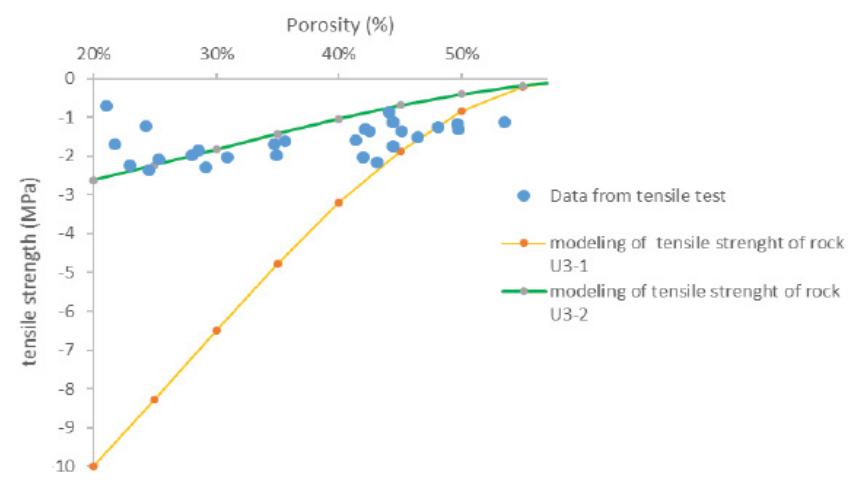

Figure 20: Tensile curve as a function of porosity. 
on the mechanical strengths seems to be limited to the range of a quasisaturation domain, where the suction is "approximately" lower than the air entry value. The dependency of the mechanical strength with the water content (or suction) indicates the susceptibility of the studied rock to modify its physical characteristics (such as porosity) with the variation of the environmental conditions (such as humidification and drying cycles). Naturally, because of the heterogeneity characteristic of the samples, it is not evident to obtain the same initial conditions, in particular, porosity.

From the three bending tests, we deduce that the rate UCS/UTS varied from 5 to 1 when porosity increases from 0.2 to 0.48 for dry state and from 2 to 1 for the same porosity range's variation for saturated samples. The calibration of the Li and Aubertin model [63] seems to be sufficient to predict the UCS and UTS dependency on porosity.

Finally, understanding the mechanical behavior of limestone as a principal constituent of "El Haourai" caves and the effect of porosity and water content, both related to the environmental conditions of caves, should lead to optimize the supervision of the caves particularly the birth and propagation of cracks.

\section{Conclusion}

The object of this work, concerns the hydro-mechanical behavior rock $U 3$ aiming to give some quantitative relations of the strengths and stiffness evolutions with the water content as a variable parameter due to environmental cycles and its effect on porosity. Porosity increase was retained as a key parameter linked to the decrease of strengths. The investigation of the microstructure of the limestone rock $U 3$ provided from the monument of El-Haouaria caves shows the mineralogy of the rock, which consists primarily of calcite and quartz. The grains are of marine origin with a variable shape inducing a variable porosity. The cement connecting the grains is very fine and the porosity is a very important sign that the rock is a soft rock. Rock porosity varies from one sample to another (U3.1-U3.2), and it has undergone changes over time by the presence of cements. This modification was caused by the dissolution of the mineral salts present in the rock or coming from the seawater (crystallization, presence of halite...) From the water retention curve, it was shown that the saturation water content is well dependent on porosity; air entry value is very low, which is a sign of non-presence of clay. The grains of the rocks have a coarse dimension equivalent to sand. The shape of the retention curve is closely related to porosity. The curve showed the hysteretic behavior of the rock, which can be explained also by the role of porosity.

The results of the mechanical tests conducted on the limestone rock samples show the important influence of the porosity on both, compression strength and tensile strength. At a dried condition, the compression strength varies from $14 \mathrm{MPa}$ for the porosity of $33 \%$ to $4 \mathrm{MPa}$ for the porosity of $48 \%$. However, at a saturated condition, the compression strength varies from $4.5 \mathrm{MPa}$ for the porosity of $34 \%$ to $2 \mathrm{MPa}$ for the porosity of $44 \%$. The results show that the degree of critical saturation that causes rock strength reduction is around $95 \%$ for the whole range of rock porosities. It can be deduced that the significant effect of the water content on the mechanical strengths seems to be limited to the range of the quasi-saturation domain, where the suction is "approximately" lower than the air entry value. The dependency of the mechanical strength with the water content (or suction) indicates the susceptibility of the studied rock to modify its physical characteristics (such as porosity) with the variation of the environmental conditions (such as humidification and drying cycles).

From the three bending tests, it was deduced that the rate UCS/
UTS varied from 5 to 1 when porosity increases from 0.2 to 0.48 for dry state and from 2 to 1 for the same porosity range variation for saturated samples. The calibration of the "Li and Aubertin model" was sufficient to predict the UCS and UTS dependency with porosity. Finally, understanding the mechanical behavior of limestone as a principal constituent of "El Haourai" caves and the effect of porosity and water content, both related to the environmental conditions of the caves, should lead to optimize the monitoring of the caves particularly the birth and growth of cracks.

\section{References}

1. Yu S, Oguchi CT (2010) Role of pore size distribution in salt uptake, damage and predicting salt susceptibility of eight types of Japanese building stones. Eng Geol 115: 226-236.

2. Kloppmann $W$, Bromblet $P$, Vallet $J M$, Vergès-Belmin $V$, Rolland $O$, et al (2011) Building materials as intrinsic sources of sulphate: A hidden face of salt weathering of historical monuments investigated through multi-isotope tracing (B, O, S). Sci Total Environ 40: 1658-1669.

3. Al-Omari A, Beck K, Brunetaud X, Török Á, Al-Mukhtar M (2015) Critical degree of saturation: A control factor of freeze-thaw damage of porous limestones at Castle of Chambord. France Eng Geol 185: 71-80.

4. Aldoasri MA, Darwish SS, Adam MA, Elmarzugi NA, Ahmed SM (2017) Enhancing the durability of calcareous stone monuments of ancient Egypt using $\mathrm{CaCO}_{3}$ nanoparticles. Sustainability, 9: 1392.

5. Rahmouni A, Boulanouar A Samaouali A, Boukalouch M, Géraud Y, et al. (2017) Prediction of elastic and acoustic behaviors of calcarenite used for construction of historical monuments of Rabat, Morocco. J Rock Mech Geotech Eng (JRMGE) 9: 74-83.

6. Baud P, lle Kleina E, Wongb Tf (2004) Compaction localization in porous sandstones: spatial evolution of damage and acoustic emission activity. $J$ Struct Geol 26: 603-24.

7. Evans B, Fredrich JT, Wong TF (1990) The brittle-ductile transition in rocks: Recent theoretical and experimental progress. Geophys Monogr 56: 1-20.

8. Nicolas A, Fortin J, Regnet JB, Dimanov A, Gueguen Y (2016) Brittle and semibrittle behaviours of a carbonate rock: influence of water and temperature. Geophys J Int 206: 438-456.

9. Baud P, Wong TF, Zhu W (2014) Effects of porosity and crack density on the compressive strength of rocks. Int- J Rock Mech Min Sci 67: 202-211.

10. Zheng J, Zheng L, Liu HH, Ju Y (2015) Relationships between permeability, porosity and effective stress for low-permeability sedimentary rock. Int J Rock Mech Min Sci 78: 304-318,.

11. Regnet JB, David C, Fortin J, Robion P, Makhloufi Y, et al. (2015) Influence of microporosity distribution on the mechanical behavior of oolithic carbonate rocks. Geomech Energy Environ 3: 11-23.

12. Wiesmaier S, Heap MJ, Branca S, Albert GH, Kueppers U, et al. (2015) Variability in composition and physical properties of the sedimentary basement of Mt Etna. Italy J Volcanol Geotherm Res 302: 102-116.

13. Dan M, Zilong Z, Jiangyu W, Qiang L, Haibo B (2017) Grain size distribution effect on the hydraulic properties of disintegrated coal mixtures. Energies 10 : 612.

14. Beck K (2006) Etude des propriétés hydriques et des mécanismes d'altération de pierres calcaires à forte porosité. PhD Thesis University of Orleans, France. $p: 245$

15. Takarli M, Prince W, Siddique R (2008) Damage in granite under heating/ cooling cycles and water freeze-thaw condition. Int J Rock Mech Min Sci 45: 1164-1175.

16. Baud P, Vinciguerra S, David C, Cavallo A, Walker E, et al. (2009) Compaction and failure in high porosity carbonates: Mechanical data and microstructural observations. Pure Appl Geophys 166: 869-898.

17. Tan X, Chen W, Yang J, Cao J (2011) Laboratory investigation on the mechanical properties degradation of granite under freeze-thaw cycles. Cold Reg Sci Technol 68: 130-138.

18. Bayram $F$ (2012) Predicting mechanical strength loss of natural stones afte freeze-thaw in cold regions. Cold Reg Sci Technol 83: 98-102. 
Citation: Koubaa Y, Jamei M, Guiras H (2018) Hydro-mechanical Properties of Highly porous Limestone Rock used for Historic Monuments in NorthEast Tunisia. J Civil Environ Eng 8: 310. doi: 10.4172/2165-784X.1000310

Page 11 of 11

19. Avşar E, Ulusay $R$, Mutlutürk $M$ (2015) An experimental investigation of the mechanical behavior and microstructural features of a volcanic soil (Isparta, Turkey) and stability of cut slopes in this soil. Eng Geol 189: 68-83

20. Chunshun Z, Jian J, Jayantha K, Yilin G (2017) Evaluation of the performance of a breakage model for high porosity Haubourdin chalk. Computers and Geotechnics 90: 113-119.

21. Shengjun M, Hui W, Meifeng C, Yuanfang S, Jintao M (2018) Damage constitutive model and variables of cracked rock in a hydro-chemical environment. Arabian Journal of Geosciences 11: 19.

22. Benavente D, Garcõa del Curab MA, BernabeÂua A, OrdoÂnÄeza S (2001) Quantification of salt weathering in porous stones using an experimental continuous partial immersion method. Eng Geol 59: 313-325.

23. Vajdova V, Zhu W, Chen TMN, Wong TF (2010) Micromechanics of brittle faulting and cataclastic flow in Travel limestone. J Struct Geol 32: 1158-1169.

24. Vajdova V, Baud P, Wu L, Wong TF (2012) Micro-mechanics of inelastic compaction in two allochemical limestones. J Struct Geol 43: 100-117.

25. Sarışık A, Sarışık G (2016) Investigation of engineering characteristics of mardin stone used in eco-building. Journal Cogent Engineering 3: 257412.

26. Honglina Z, Xiangjunb L, Guanghuac $Y$, Qiao CH, Yanhua T, et al. (2016) Determination of water-lock critical value of low-permeability sandstones based on digital core. Natural Gas Industry B 3: 253-259.

27. Wei X, Duc M, Hattab M, Reuschle T, Taibi S, Fleureau JM (2017) Effect of decompression and suction on macroscopic and microscopic behavior of a clay rock. Acta Geotechnica 12: 47-65.

28. Fagerlund G (1977a) The critical degree of saturation method of assessing the freeze/thaw resistance of concrete. Materials and Structures 10: 217-229.

29. Fagerlund G (1977b) The international co-operative test of the critical degree of saturation method of assessing the freeze/thaw resistance of concrete. Materials and Structures 58: 231-253.

30. Price AM, Farmer IW (1979) Application of yield models to rock. Int J Rock Mech Min Sci 16: 157-159.

31. Daoud HS, Rashed KA, Alshkane YM (2017) Correlations of uniaxial compressive strength and modulus of elasticity with point load strength index Pulse velocity and dry density of limestone and sandstone rocks in Sulaiman Governorate, Kurdistan Region, Iraq. JZS (Part A) 19: 3.

32. Diederichs MS (2000) Instability of hard rock masses: The role of tensile damage and relaxation. (Unpublished $\mathrm{PhD}$ ) Thesis, extended abstract and summary. University of Waterloo, Canada.

33. Diederichs MS (2003) Rock fracture and collapse under low confinement conditions. Rock Mech Rock Eng 36: 339-381

34. Descamps F, Ramos Da Silva M, Schroeder C, Verbrugge JC, Tshibangu JP (2012) Limiting envelopes of a dry porous limestone under true triaxial stress states. Int J Rock Mech Min Sci 56: 88-99.

35. Arzúa J, Alejano LR (2013) Dilation in granite during servo-controlled triaxia strength tests. Int J Rock Mech Min Sci 61: 43-56.

36. Walton G, Arzúa J, Alejano LR, Diederichs MS (2015) Laboratory-testingbased study on the strength, deformability, and dilatancy of carbonate rocks at low confinement rock. Mech Rock Eng 48: 941-958.

37. Vajdova V, Baud P, Wong TF (2004) Compaction, dilatancy, and failure in porous carbonate rocks. J Geophys Res p: 109

38. Nicolas A, Fortin J, Regnet JB, Dimanov A, Guéguen Y (2016) Brittle and semibrittle behaviours of a carbonate rock: influence of water and temperature. Geophys J Int 206: 438-456.

39. Pineda JA, Alonso EE, Romero E (2014a) Environmental degradation of claystones. Géotechnique 64: 64-82.

40. Pineda JA, Romero E, De Gracia M, Sheng D (2014b) Shear strength degradation in claystones due to environmental effects. Géotechnique 64: 493-501.
41. Vicol T (1990) Comportement hydraulique et mécanique d'un sol fin non saturé, Application à la modélisation Thèse de Doctorat, Ecole Nationale des Ponts et Chaussées, Cermes, Paris.

42. Delage P, Cui A (1996) Microstructure of a compacted silt. Can Geotech $J$ 33: $150-158$.

43. Ng CWW, Pang YW (2000a) Influence of stress state on soil water characteristic and slope stability. J Geotech Geoenviron Eng, ASCE 126: 157-166.

44. Soldi M, Guarracino L, Jougnot D (2017) A simple hysteretic constitutive model for unsaturated flow. Transport in Porous Media 120: 271-285.

45. Vanapalli SK, Fredlund DG, Pufahl DE (1999) The influence of soil structure and stress history on the soil-water characteristics of a compacted till. Géotechnique 49: 143-159.

46. Buisson MSR, Wheller SJ (2000) Inclusion of hydraulic hysteresis in a new elasto-plastic framework for unsaturated soils. In: Tarantino A, Mancuso C (Eds). Experimental evidence and theoretical approaches in unsaturated soils. 2: $109-119$

47. Ng CWW, Pang YW (2000b) Experimental investigation of soil-water characteristics of a volcanic soil. Can Geotech J 37: 1252-1264.

48. Alonso EE, Cardoso R (2010) Behavior of materials for earth and rockfill dams: Perspective from unsaturated soil mechanics. Front Archit Civ Eng China 4: 1-39.

49. Van Genuchten MTH (1980) A closed-form equation for predicting the hydraulic conductivity of unsaturated soils. Soil Sci Am J 44: 892-898.

50. Rampino C, Mancuso C, Vinale F (1999) Laboratory testing on an unsaturated soil: equipment, procedures and first experimental results. Can Geotech J 3: 1-12.

51. Romero E (1999) Characterization and thermo-hydro-mechanical behavio of unsaturated boom clay Dissertation for the Doctoral Degree Barcelona Universitat Politècnica de Catalunya, Spain.

52. Romero E, Vaunat J (2000) Retention curves of deformable clays In: Tarantino A, Mancuso C, (eds) Experimental evidence and theoretical approaches in unsaturated soils. Trento, Italy Rotterdam: Balkema: 91-106.

53. Sun DA, Sheng DC, Cui HB, Sloan SW (2007) A density-dependent elastoplastic hydro- mechanical model for unsaturated compacted soils. Int J Num Analytical Methods Geomech 3: 1257-1279.

54. Parajul K, Sadeghi M, Jones SB (2017) A binary mixing model for characterizing stony- soil water retention. Agricultural and Forest Meteorology 244: 1-8.

55. Dobereiner L, Freitas MM (1986) Geotechnical properties of weak sandstones Géotechnique 36: 79-94.

56. Dessandier, D (1995) Etude du milieu poreux et des propriétés de transfert de fluide du tuffeau blanc de Tourraine, application à la durabilité des pierres en œuvre PhD thesis, University de Tours, France.

57. Hoek E, Bieniawski ZT (1965) Brittle fracture propagation in rock under compression. Int J Fract 1: 137-155.

58. Brace WF, Paulding Jr BW, Scholz C (1966) Dilatancy in the fracture of crystalline rocks. J Geophys Res 71: 3939-3953.

59. Scholz $\mathrm{CH}$ (1968) Microfracturing and the in-elastic deformation of rock in compression. J Geophys Res, 73: 1417-1432.

60. Winkler EM (1985) A durability index for stone. Proceedings of the $5^{\text {th }}$ International Congress on Deterioration and Conservation of stone, Lausanne 25-27 November 1985, Presses Polytechniques Romandes 1: 151-156.

61. Jeng FS, Huang TH (1999) The holding mechanism of under-reamed rockbolts in soft rock. Int J Rock Mech Min Sci 36: 761-775.

62. Homand F, Duffaut P (2000) Manuel de Mécanique des Roches, Comité français de Mécanique des roches.

63. Li L, Aubertin M (2003) A general relationship between porosity and uniaxia strength of engineering materials. Can J Civ Eng 30: 644-658. 